\title{
LETTER
}

\section{Resource availability controls fungal diversity across a plant diversity gradient}

Mark P. Waldrop, ${ }^{1 *}$ Donald R. Zak, ${ }^{1,2}$ Christopher B. Blackwood, ${ }^{1}$ Casey D. Curtis ${ }^{1}$ and David Tilman ${ }^{3}$ ${ }^{1}$ School of Natural Resources and Environment, University of Michigan, Ann Arbor, MI 481091115, USA

${ }^{2}$ Department of Ecology \& Evolutionary Biology, University of Michigan, Ann Arbor, MI 48109-1048, USA

${ }^{3}$ Department of Ecology,

Evolution and Behavior, University of Minnesota, 1987 Upper Buford Circle, St Paul, MN 55108, USA

*Correspondence and present address: Mark P. Waldrop, US Geological Survey, 345 Middlefield Rd, MS 962, Menlo Park, CA 94025, USA. E-mail: mwaldrop@usgs.gov

\begin{abstract}
Despite decades of research, the ecological determinants of microbial diversity remain poorly understood. Here, we test two alternative hypotheses concerning the factors regulating fungal diversity in soil. The first states that higher levels of plant detritus production increase the supply of limiting resources (i.e. organic substrates) thereby increasing fungal diversity. Alternatively, greater plant diversity increases the range of organic substrates entering soil, thereby increasing the number of niches to be filled by a greater array of heterotrophic fungi. These two hypotheses were simultaneously examined in experimental plant communities consisting of one to 16 species that have been maintained for a decade. We used ribosomal intergenic spacer analysis (RISA), in combination with cloning and sequencing, to quantify fungal community composition and diversity within the experimental plant communities. We used soil microbial biomass as a temporally integrated measure of resource supply. Plant diversity was unrelated to fungal diversity, but fungal diversity was a unimodal function of resource supply. Canonical correspondence analysis (CCA) indicated that plant diversity showed a relationship to fungal community composition, although the occurrence of RISA bands and operational taxonomic units (OTUs) did not differ among the treatments. The relationship between fungal diversity and resource availability parallels similar relationships reported for grasslands, tropical forests, coral reefs, and other biotic communities, strongly suggesting that the same underlying mechanisms determine the diversity of organisms at multiple scales.
\end{abstract}

\section{Keywords}

microbial diversity, fungal diversity, plant diversity, Cedar Creek Natural History Area, microbial biomass, resource availability, diversity-productivity hypothesis.

Ecology Letters (2006) 9: 1127-1135

\section{INTRODUCTION}

Soils support a wide array of biological diversity making them one of the most diverse habitats on Earth (Tiedje et al. 1999; Tunlid 1999). Although there is uncertainty surrounding current estimates of microbial diversity in soil, conservative measures suggest soils contain $10^{3}-10^{6}$ prokaryotic species per gram and on the order of 1.5 million fungal species worldwide (Torsvik et al. 1990; Hawksworth 2004; Gans et al. 2005). Despite a rich body of theory contributing to our understanding of diversity in plant and animal communities, we presently lack a theoretical foundation to explain the wealth of microbial diversity in soil (Tunlid 1999; Hooper et al. 2000). Do a common set of factors govern the diversity of all biotic communities, whether they are composed of microorganisms, plants or animals? Uncover- ing the underlying mechanisms fostering microbial diversity in soil will contribute to theories concerning the regulation of biodiversity in general, and to our understanding of microbial communities in soil which mediate a myriad of ecosystem processes.

Microbial communities in soil are largely structured by the supply of growth limiting substrates which enter soil via plant detritus and root exudation (Zak et al. 1994, 2003). There are at least two mechanisms whereby plant communities, which control resource supply to heterotrophic microbial communities, could influence fungal diversity in soil. First, the productivity-diversity bypothesis proposes that the availability of growth-limiting resources limits the diversity of biotic communities (Tilman 1982; Tilman et al. 1996). Therefore, higher levels of plant detritus production should increase supply of limiting resources (i.e. organic substrates) 
thereby increasing the size of the microbial community with concomitant increases in diversity (Kennedy \& Smith 1995; Hooper et al. 2000; Maclean et al. 2005). Studies utilizing molecular techniques find that bacterial diversity in aquatic ecosystems is related to resource availability, although the form of the relationship is complex (Kassen et al. 2000; Horner-Devine et al. 2003; Maclean et al. 2005). Our understanding of how resource availability influences microbial diversity in soil is limited, with one observation suggesting that bacterial diversity was positively related to resource availability in a comparison of soils under organic (high resource availability) and conventional (low resource availability) agricultural management (Ovreas \& Torsvik 1998). To our knowledge, the relationship between diversity of fungal communities and resource availability remains unexplored.

As an alternative to the aforementioned hypothesis, the plant diversity bypothesis proposes that greater plant diversity increases the range of organic substrates entering soil thus creating niche space to be filled by a greater array of heterotrophic microorganisms (Lodge 1997; Hooper et al. 2000; Brodie et al. 2003). Greater plant diversity also could exert a positive influence on fungal diversity by increasing microclimate variability and habitat complexity (e.g. soil pore space, root architecture; Hooper et al. 2000). Nevertheless, studies examining the linkages between plant diversity and microbial diversity have not yielded a consistent viewpoint (Broughton \& Gross 2000; Hooper et al. 2000; Kowalchuk et al. 2002; Brodie et al. 2003; Carney et al. 2004). In part, this situation has resulted from the use of natural plant diversity gradients which contain many factors that co-vary with plant diversity (Broughton \& Gross 2000; Brodie et al. 2003; Carney et al. 2004). Moreover, many other factors unrelated to plants, but inherent to soil (climate, parent material, slope), may influence fungal diversity and they are not easily controlled.

Here, we use molecular techniques to test these two alternative mechanisms using the soil fungal community because it plays a major functional role within ecosystem carbon and nutrient cycling. Additionally, we have focused on soil fungi because fungal abundance has been observed to increase with greater plant diversity (Zak et al. 2003). Our investigation of fungal diversity was carried out at the Cedar Creek Natural History Area (CCNHA), in which experimental plant diversity treatments containing one to 16 grassland-savanna species have been maintained for a decade (Tilman et al. 2001). The common garden design of the experiment allows for examination of direct relationships between plant and fungal diversity while minimizing potential covarying factors. Plant diversity, plant productivity, and microbial biomass are positively related in this experiment, wherein greater plant species richness leads to increased plant productivity, detritus production and microbial biomass (Zak et al. 2003). Therefore, we used microbial biomass as an integrated measure of resource availability over the course of this decade-long experiment. This experimental approach enabled us to discern whether: (1) soil fungal diversity was directly related to plant diversity; or (2) fungal diversity responded directly to greater resource availability. We also explored whether plant diversity and/or resource availability affected fungal community composition.

\section{METHODS}

\section{Location}

The CCNHA is located c. $50 \mathrm{~km}$ north of Minneapolis, MN, USA. It is a 2200 ha experimental ecological reserve containing oak savannas, prairies, hardwood forests, pine forests, ash and cedar swamps, acid bogs, marshes and sedge meadows. The soils of Cedar Creek are formed from a glacial outwash sandplain. Cedar Creek has a continental climate with hot summers, cold winters and precipitation is $66 \mathrm{~cm}$ year $^{-1}$ which occurs throughout the year.

\section{Field experiments}

\section{Field site description}

The CCNHA biodiversity experiment was created in 1993 from an abandoned agricultural field. To prepare the plots, the old field was burned and treated with herbicide to kill the remaining plants. A portion of the mineral surface soil was removed ( 0 to $c .8 \mathrm{~cm})$ to minimize the seed bank, and the site was then ploughed and harrowed. In spring of 1994, 342 plots $(9 \mathrm{~m} \times 9 \mathrm{~m})$ containing $1,2,4,8$ or 16 grasslandsavanna species were established by separate random draws from a pool of 18 species consisting of C4 and C3 grasses, legumes, forbs and trees. Each plot was planted with a total of $10 \mathrm{~g}$ seed $\mathrm{m}^{-2}$ in 1994 and $5 \mathrm{~g}$ seed $\mathrm{m}^{-2}$ in 1995; equal masses of each species composed a specific treatment. Species used in this experiment included Andropogon gerardi, Agropyron smithii, Amorpha canescens, Astragalus canadensis, Buchloe dactyloides, Elymus canadensis, Koeleria cristata, Lespedeza capatata, Lupinus perennis, Panicum virgatum, Schizachyrium scoparium, Poa pratensis, Sorghastum nutans, Petalosetmum purpureum, Sporobolus cryptandrus, Monarda fistulosa, Quercus ellipsoidalis and Q. macrocarpa. Plant diversity treatments are maintained by frequent hand weeding and soil disruption was kept to a minimum.

In October 2003, soil was collected in 116 of the 342 total plots to a depth of $20 \mathrm{~cm}$ using a $2.5 \mathrm{~cm}$ diameter corer. The 116 plots consisted of 39 one-species plots, 24 twospecies plots, 12 four- and eight-species plots, and 29 16-species plots. All soil sampling occurred in 1 day. Six soil cores were collected at predetermined locations in each plot. Soil from each plot was combined in a plastic bucket, 
homogenized by hand, and a subsample was placed in a plastic bag. The remaining soil was returned to the holes in the plot, and the subsamples were placed in a cooler with dry ice. The cooler was transported to the University of Michigan and stored at $-80{ }^{\circ} \mathrm{C}$ within $24 \mathrm{~h}$ of field collection.

\section{Microbial biomass}

We quantified viable microbial biomass in this experiment using the phospholipid fatty acid (PLFA) technique (sensu Zak et al. 2003), a technique that includes both bacterial and fungal biomass. The quantity of total PLFAs $(<20: 0)$ is directly proportional to microbial biomass (Zelles et al. 1995). Freeze-dried soil from each plot was extracted with a single-phase, phosphate-buffered $\mathrm{CHCl}_{3}-\mathrm{CH}_{3} \mathrm{OH}$ solvent. The extracted lipids were then separated into functional classes using silicic acid column chromatography. The polar lipid fraction was transesterified into fatty acid methyl esters (FAMEs) using a mild-alkaline system containing methanol. The resulting FAMEs were separated and identified using an Agilent 6890 GC interfaced to an Agilent 5973 mass selective detector (Agilent, Schaumburg, IL, USA). We used both internal and external PLFA standards to control for recovery and loss.

\section{Molecular analyses}

We did not extract DNA from all 116 plots; we excluded 12 one-species plots, two two-species plots, and four 16-species plots. We extracted DNA from the remaining 98 plots using the Ultraclean Soil DNA extraction kit (Mo Bio Laboratories Inc., Carlsbad, CA, USA). DNA was visualized on a $1 \%$ agarose gel and quantified with Picogreen (Stratagene, La Jolla, CA, USA). DNA was diluted to $6.0 \mathrm{ng} \mu \mathrm{L}^{-1}$, and PCR amplified using the forward primer ITS-1F (5'-CTT GGT CAT TTA GAG GAA GTA A-3') and the reverse primer ITS-4 (5'-TCC TCC GCT TAT TGA TAT GC-3'). These primers are specific to the fungal internal transcribed spacer (ITS) region of genomic DNA (White et al. 1990). We used the Expand High Fidelity PCR system as our reagents (Roche Applied Science, Indianapolis, IN, USA). The PCR program was 30 cycles with $94{ }^{\circ} \mathrm{C}(1 \mathrm{~min})$ melting, $55^{\circ} \mathrm{C}(30 \mathrm{~s})$ annealing, and $72^{\circ} \mathrm{C}(1 \mathrm{~min})$ extension temperatures, with a final 5 min extension step $\left(72^{\circ} \mathrm{C}\right)$. We attempted to minimize PCR bias by ensuring that we had the same DNA concentrations and the same PCR conditions for all samples. We also confirmed that PCR product was equally strong and specific (no background smear or dimers) prior to RISA and cloning. Although we controlled for soil DNA concentrations, environmental samples contain different bacterial to fungal to plant to animal DNA ratios, making it difficult to accurately control for microbial DNA concentrations. We used $99 \%$ similarity in our clustering of Operational Taxonomic Units (OTUs, see below), which should reduce PCR artefacts associated with polymerase mistakes (Acinas et al. 2005).

Ribosomal intergenic spacer analysis (RISA) was performed on the 98 samples by measuring the length heterogeneity of the ITS region on polyacrylamide gels. PCR products $(5 \mu \mathrm{L})$ were run on a $5 \%$ polyacrylamide gel for $18 \mathrm{~h}$ at $50 \mathrm{~V}$ (DCODE gel system, Bio-Rad, Hercules, CA, USA); $100 \mathrm{bp}$ ladders were run as size standards. Following the run, the polyacrylamide gel was separated from the glass plate and stained with ethidium bromide (20 min), rinsed with water $(20 \mathrm{~min})$, transferred to a UV light table, and digitally photographed. Size standards in each gel were used to calculate sizes of ITS regions using Labworks Image Acquisition and Analysis Software (UVP Inc., Upland, CA, USA).

The presence/absence matrix of ITS banding patterns among plots was analysed by distance-based redundancy analysis (Legendre \& Anderson 1999), with one minus the Jaccard coefficient of similarity used to define distance between profiles. Distance calculation and principal coordinates analysis were performed in Proc IML in SAS, and redundancy analysis was performed in Canoco 4.0 (Microcomputer Power, Ithaca, NY, USA). The hypotheses that ITS banding patterns were affected by plant diversity treatment or total PLFA abundance were tested by 9999 random permutations of sample identity. Total numbers of bands were compared among the plant diversity treatments using a one-way ANOVA. We also used regression analysis to determine if ITS band richness was explained by microbial biomass.

We used cloning and sequencing on a subset of samples to obtain a detailed assessment of fungal diversity. We randomly chose five replicates from each of the 1, 4, 8 and 16 plant species treatments for cloning and sequencing; however, nine were removed from fungal diversity statistical analysis because they did not meet our lower bound for adequate sampling effort (viz. number of clones, see below). In our final analysis, we had five one-species plots: three contained legumes (A. canescens, Petalostemum purpureum and L. perennis), one contained a forb (Liatris aspera), and one contained a woody species (Q. ellipsoidalis). We had two fourspecies plots: one four-species plot included a legume, a C3 grass, a woody species, and a C4 grass; the other plot with four plant species contained C3 and C4 grasses and two forbs. We had one eight-species plot and three 16-species plots that included all five plant functional groups (C3 and C4 grasses, legumes, forbs and woody species, Table 1).

In 2002 and 2004, total carbon and nitrogen in soil $(0-20 \mathrm{~cm})$ were measured in each plot using a CE Elantech NC 1500 (CE Elantech, Lakewood, NJ, USA; Table 1). The average $C$ and $N$ content of years 2002 and 2004 is reported in Table 1 (mean $\pm 1 \mathrm{SD}, n=2$ ). Above and belowground plant biomass was determined in 2003 using destructive 
Table 1 Description of the plots used for fungal diversity assessment

\begin{tabular}{|c|c|c|c|c|c|c|}
\hline $\begin{array}{l}\text { Plot } \\
\text { number* }\end{array}$ & $\begin{array}{l}\text { Plant species } \\
\text { richness }\end{array}$ & Functional group & $\begin{array}{l}\text { Aboveground } \\
\text { biomass }\left(\mathrm{g} \mathrm{m}^{-2}\right)\end{array}$ & $\begin{array}{l}\text { Root biomass } \\
\left(\mathrm{g} \mathrm{m}^{-2}\right)\end{array}$ & $\mathrm{C}\left(\mathrm{g} \mathrm{kg}^{-1}\right)$ & $\mathrm{N}\left(\mathrm{g} \mathrm{kg}^{-1}\right)$ \\
\hline 265 & 1 & Legume & 255 & 772 & $7.58 \pm 1.51$ & $0.68 \pm 0.13$ \\
\hline 137 & 1 & Legume & 622 & 437 & $5.35 \pm 0.25$ & $0.49 \pm 0.02$ \\
\hline 151 & 1 & Woody & 215 & 660 & $4.40 \pm 2.16$ & $0.37 \pm 0.13$ \\
\hline 167 & 1 & Forb & 205 & 314 & $6.35 \pm 4.24$ & $0.54 \pm 0.32$ \\
\hline 205 & 1 & Legume & 159 & 502 & $6.77 \pm 2.35$ & $0.60 \pm 0.25$ \\
\hline 53 & 4 & C3, C4, legume, woody & 151 & 824 & $5.53 \pm 2.28$ & $0.45 \pm 0.17$ \\
\hline 138 & 4 & $\mathrm{C} 3$, forb & 232 & 535 & $7.21 \pm 2.84$ & $0.62 \pm 0.23$ \\
\hline 115 & 8 & C3, C4, forb, woody & 79 & 739 & $5.94 \pm 1.07$ & $0.50 \pm 0.06$ \\
\hline 9 & 16 & C3, C4, forb, legume, woody & 323 & 1315 & $3.94 \pm 0.70$ & $0.33 \pm 0.00$ \\
\hline 68 & 16 & C3, C4, forb, legume, woody & 389 & 870 & $5.15 \pm 0.75$ & $0.41 \pm 0.04$ \\
\hline 174 & 16 & C3, C4, forb, legume, woody & 408 & 1156 & $8.52 \pm 2.56$ & $0.70 \pm 0.19$ \\
\hline
\end{tabular}

*Plot number is unique to the Cedar Creek Natural History Area Biodiversity experiment. See the CCNHA LTER webpage (http:// cedarcreek.umn.edu/research/exper/e120/) for more information on species.

harvest methodologies similar to that described in Zak et al. (2003) (Table 1). Here, we only report those values for the samples from cloning and sequencing analysis, because soil and plant characteristics for the entire experiment have been previously published (Zak et al. 2003).

We cloned the amplified sequences using the pGEM-T Vector system (Promega Corporation, Madison, WI, USA) following the protocol of the manufacturer. Ligation reactions were incubated overnight at $4{ }^{\circ} \mathrm{C}$, and we used the high-efficiency competent cells provided by Promega. All colonies with inserts were selected from each sample and grown overnight in LB broth. We extracted the plasmids from the colonies using the Wizard Plus SV Minipreps DNA purification system (Promega Corporation). Cloned inserts were sequenced by the DNA sequencing CORE at the University of Michigan using T7 and SP6 primers. The DNA sequences have been submitted to the GenBank database (accession numbers DQ420681-DQ421315).

Contiguous DNA sequences (500-800 bp) were created from the forward and reverse sequence data. Sequence data from all the clones were imported into the ARB software package for alignment. Distances between sequences were calculated using 276 conserved positions from the partial $18 \mathrm{~S}, 5.8 \mathrm{~S}$, and partial $28 \mathrm{~S}$ regions using the Jukes-Cantor correction method. ITS regions which could not be aligned were not used in our clustering algorithm. The distance matrix was exported from ARB, and the UPGMA clustering algorithm of Proc Cluster in SAS (Cary, NC, USA) was used to cluster the OTUs based on genetic distance. Clusters defined by $99 \%$ or greater similarity were extracted from this analysis using Proc Tree, and these were subsequently considered operational taxonomic units (OTUs). OTUs were further evaluated by BLAST searching in GenBank (see Tables S1-S3 in Supplementary Material). This resulted in 149 unique OTUs for the entire data set. Community analysis was performed on sequence OTU frequencies (counts) using canonical correspondence analysis (Ter Braak 1986). Plant diversity was treated as a continuous variable when analysing OTU frequencies due to the limited number of samples characterized by sequencing.

Fungal diversity was calculated by the generation of rarefaction curves with the EstimateS software package (Colwell 1994-2004) in order to correct for differences in clone library size among samples (Fig. 1). Rarefaction curves deviated from the 1:1 line and were beginning to reach an asymptote, indicating that we were approaching an adequate sampling of fungal diversity. We chose the nonparametric Incidence-based Estimator (ICE) method to estimate fungal OTU richness (Hughes \& Bohannan 2004). The ICE

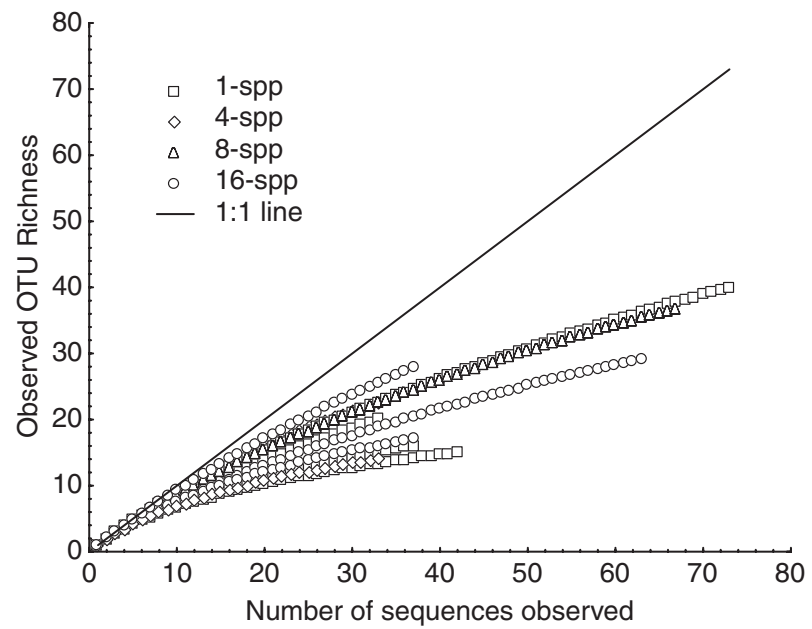

Figure 1 Rarefied curves of observed fungal diversity. Rarefied curves were generated using EstimateS software by averaging 50 randomizations of the observed operational taxonomic unit (OTU) accumulation curve. 
estimator is based on species found in $<10$ sampling units, thus giving greater importance to the rarer species (Chazdon et al. 1998; Hughes \& Bohannan 2004). Other diversity calculations from EstimateS software (e.g. Chao1, ACE and Shannon), were highly correlated with ICE $(r>0.73)$. We chose a clone library size of 33 in order to obtain the greatest number of samples while still encountering the majority of the OTUs from any particular sample. Nine samples did not meet a minimum clone library size of 33 and were not used to estimate fungal diversity; these samples contained between 14 and 26 clones. To identify the phylogenetic affiliation of OTUs, we then submitted each entire sequence (ribosomal + ITS) to a BLAST search in GenBank. For a text description of the dominant OTUs, see Appendix S1 in Supplementary Material.

To test whether fungal diversity increased with plant diversity or resource availability, we used linear and nonlinear regression $(n=11)$. We also compared fungal diversity among the plant diversity treatments using a oneway ANOva (Statistica, StatSoft Inc., Tulsa, OK, USA).

\section{RESULTS}

Plant diversity treatment significantly affected fungal ITS banding patterns $(P=0.001$, Fig. 2$)$, but each ordination axis accounted for only $1-3 \%$ of the variability in banding patterns, indicating that this effect is probably not biologically important. There was no significant effect of plant diversity on the frequency with which a band occurred in a treatment, indicating that differences in community com-

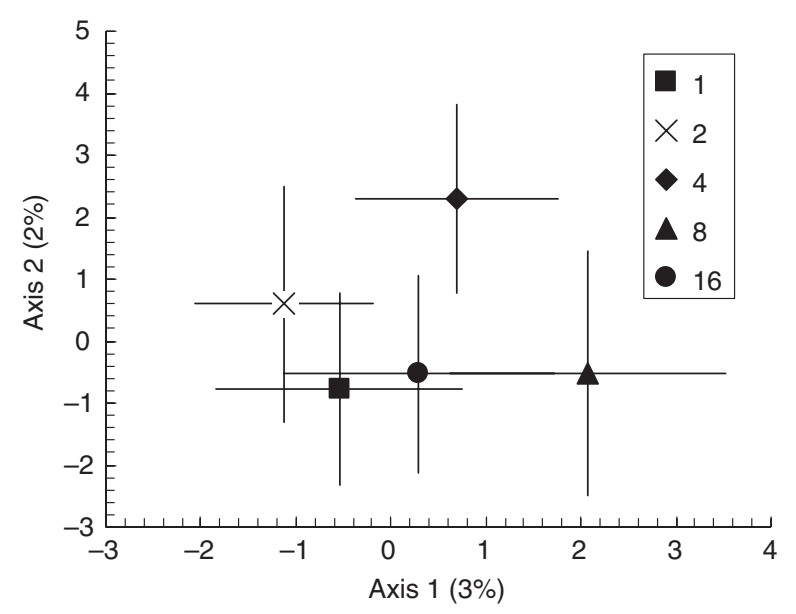

Figure 2 Ribosomal intergenic spacer analysis (RISA) of fungal communities in the plant diversity treatments. Symbols represent means \pm 1 SD. Microbial community composition was affected by plant diversity $(P=0.001)$, but the amount of variability explained by each axis was very low $(\leq 3 \%)$, precluding any biologically significant effect. position among plant diversity treatments could not be explained by any bands. There was also no significant effect of plant diversity on the number of ITS bands. ITS banding patterns and total number of bands were unrelated to microbial biomass (i.e. total PLFA; $P>0.05$ ). RISA data were analysed using presence/absence to avoid spurious changes in band intensity which can accumulate during PCR, however this procedure may mask minor changes in relative abundance. There was also no significant relationship between fungal community composition, based on OTU composition or the frequency of occurrence of an individual OTU, and plant diversity or microbial biomass $(P>0.05)$.

Using our clone library data, soil fungal diversity was unrelated to plant diversity when either regression analysis (Fig. 3a) or ANOvA was used. The range of fungal diversity values within the one and 16 plant species treatments was as large as the range of fungal diversity observed among the plant species treatments (Fig. 3a). When we tested our second hypothesis, we determined that fungal diversity was a significant unimodal function of microbial biomass, an integrated measure of resource availability (Fig. $3 \mathrm{~b}, R^{2}=$ $0.78, P=0.0003)$. This is true whether we estimated fungal diversity using ICE, ACE, Chao1 or the Shannon diversity index $(P<0.05$, data not shown). Therefore microbial biomass, and not plant diversity, was a strong predictor of fungal diversity in soil. Fungal diversity could not be explained by soil $\mathrm{C}$, soil $\mathrm{N}$, soil $\mathrm{C} / \mathrm{N}$, or aboveground, belowground, or total plant productivity $(P>0.05$, data not shown).

\section{DISCUSSION}

Plant diversity can affect the composition of the soil microbial community by altering the relative abundance of both soil fungi and bacteria, primarily due to greater plant productivity which presumably affects competitive interactions (Zak et al. 2003). Although plant diversity may have such an influence, there was little change in the composition of the fungal community. This was confirmed both through RISA analysis and analysis of sequence OTUs. RISA analysis allowed us to obtain community composition data on a large number of samples, but due to the variability in banding patterns among samples, ordination techniques could only explain a very small amount $(<3 \%)$ of variability in the data set. OTU data also indicated that there was no effect of plant diversity on fungal community composition, although our statistical power was low. For example, for the relationship between plant diversity and fungal diversity, power was 0.17 , and least significant number (LSN) was 38 . It is important to recognize that our approach measured the composition of active and inactive members of the fungal community. Plant diversity may still influence the members 


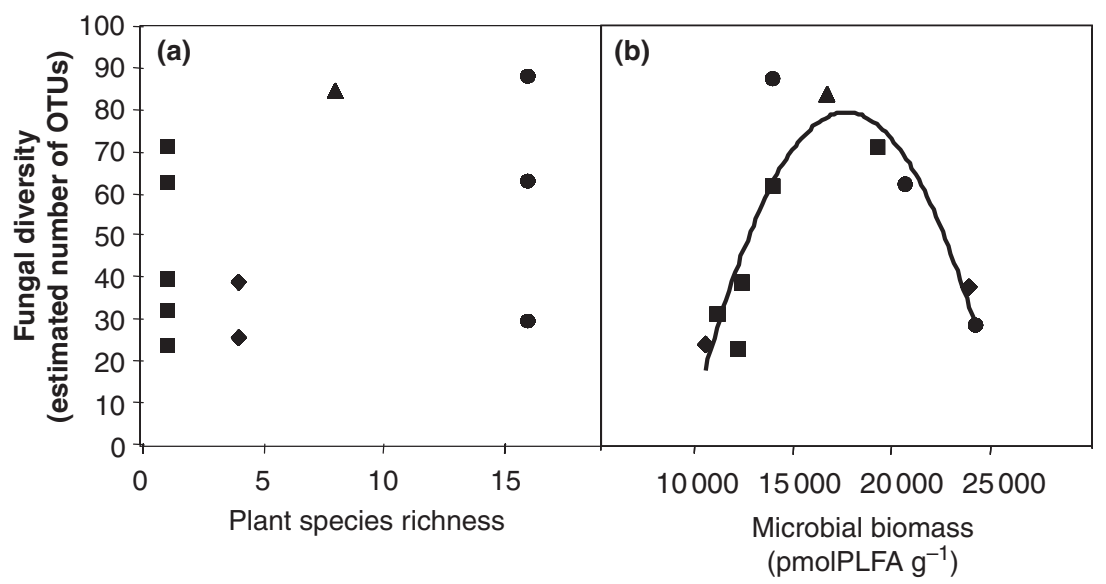

Figure 3 Plant diversity or resource control of soil fungal diversity. Fungal diversity is measured as taxonomic richness (estimated number of OTUs) based upon the incidence based estimator (ICE) from rarefaction analysis. (a) Soil fungal diversity was highly variable within any one level of plant species richness resulting in no significant relationship between plant diversity and fungal diversity $(P=0.30)$. (b) Fungal diversity was unimodally related to microbial biomass which reflects a time-integrated measure of resource availability to the microbial community $\left[R^{2}=0.78, P=0.003\right.$, equation is: fungal diversity $=-0.000001$ (pmol PLFA) ${ }^{2}+0.04$ (pmol PLFA) - 290]. Different symbols represent different plant richness treatments displayed in (a).

of the fungal community that are active, which is an area of future research.

Results from our clone library demonstrate that plant diversity does not directly affect fungal diversity per se, but plant communities directly affect fungal diversity by the limits set on microbial biomass through the supply of growth-limiting organic substrates from plant detritus production. It has been hypothesized that plant diversity could be a primary control over the diversity of microorganisms in soil (Broughton \& Gross 2000; Hooper et al. 2000; Kowalchuk et al. 2002; Brodie et al. 2003; Carney et al. 2004); however, our results clearly demonstrate plant diversity itself is not a strong predictor of fungal diversity. The lack of a relationship between plant and fungal diversity presumably arose from variability in resource availability (i.e. plant above and belowground litter production) that occurs within a given level of plant species richness. This was due, in part, to differences in productivity among different plant species and functional groups. Following from our argument, inasmuch as plant diversity may increase plant productivity and microbial biomass, fungal diversity would likely be affected.

Consumption and turnover of microorganisms by protozoans and nematodes is an important top-down control of microbial communities in soils. There are little data in the literature that predation can result in a detectable change in soil microbial biomass. For example, Mikola \& Setala (1998) clearly demonstrated that increased predation had no effect on microbial biomass in soil. Admittedly, predation can change community composition and turnover of microbial cells, but it does not tend to reduce microbial biomass. We take the consensus view that aboveground productivity, and by extension resource availability to soil microorganisms, is the primary factor controlling microbial biomass at small and large scales.

We have assumed that microbial biomass (bacterial and fungal) represents a time-integrated measure of resource availability. However, quantifying resource supply to soil microorganisms is technically elusive, and there are several reasons why microbial biomass may not accurately reflect resource supply. Foremost, resource supply is a dynamic process in which plant detritus and exudates are released into soil. These resources are consumed by heterotrophic microbial populations which experience the production of new cells as well as cell mortality, important factors which are not reflected in any measure of microbial biomass. Inasmuch, different rates of resource supply could theoretically produce identical levels of microbial biomass, if microbial production and mortality responded in concert to resource supply. We currently do not have the ability to quantify the population dynamics of complex microbial communities in soil or in any other natural environment, and our use of microbial biomass implicitly assumes that microbial production increases with resource supply while mortality remains largely unchanged or responds to a lesser extent. We contend that such an assumption is warranted because microbial biomass significantly increases with plant productivity in this experiment as well as throughout the CCNHA (Zak et al. 1990, 2003), an observation consistent with our assumption. Moreover, microbial biomass also is positively correlated with the lability of soil organic matter across multiple land-use types and ecosystems (Wardle 1992; Alvarez \& Alvarez 2000). Although microbial biomass is not itself a measure of a resource pool for microbial 
consumption, it reflects the quantity and quality of growthlimiting organic substrates, which in this experiment appears to set limits on fungal diversity in soil. Fungal diversity could not be explained by plant productivity or soil properties (e.g. total soil $\mathrm{C}$, soil $\mathrm{C} / \mathrm{N}$ ), likely because these measurements do not reflect the proportion of soil organic matter that is available for microbial growth and metabolism.

The unimodal pattern of fungal diversity predicted by microbial biomass likely occurs because few species can withstand low resource levels, and as resource availability increases, more species meet their minimum resource requirements (Rajaniemi 2003). Patterns of biotic diversity in plant and marine systems show that when resources are abundant, competitive exclusion (Rajaniemi 2003) or topdown predatory interactions (Worm et al. 2002) may lead to a reduction in diversity. Unimodal relationships between resource availability and diversity are commonly found in plant communities (Groner \& Novoplansky 2003; Rajaniemi 2003), although, as previously stated, this is one of the first studies to document this relationship in soil microbial communities. Alternatively, fungal diversity and microbial biomass may be related because they are both being affected independently by other factors such as predation or by the soil chemical and physical environment. However, we contend that they are directly related because of the strength a significant relationship (Fig. 3b) that is supported by ecological theory as well as a lack of significant effect of the aforementioned factors in this experiment.

Several hypotheses have been offered to explain patterns of bacterial diversity in soil. These hypotheses include spatial isolation in low organic matter soils and resource heterogeneity (Zhou et al. 2002). Due to differences in design among the aforementioned study and our experiment, we were not able to explicitly test among these varying hypotheses. However, in one case, if resource heterogeneity presumably increases with increasing plant diversity, our results do not support the resource heterogeneity hypothesis. At some level, spatial isolation, resource heterogeneity, and resource availability may all have some influence microbial diversity in soil. Yet the ecological mechanisms that control bacterial and fungal diversity in this environment are yet to be determined. Our analysis provides an alternative mechanistic explanation of the patterns of diversity within soil microbial communities.

The results of this study are robust at the scale of our experimental design, yet we are unable to predict how generalizable the relationship we have observed is to other locations or other scales. Net primary productivity (NPP) within the Cedar Creek biodiversity experiment spans a range typical for old fields and prairies within the region, but they are at the lower range of savannas and much lower than those in neighbouring oak forests (Ovington et al. 1963). Furthermore, soil organic matter is low in this experiment compared with other grasslands worldwide (Conant et al. 2001), in part due to pre-treatment removal of the surface soil (see Methods). We do not assume that the Cedar Creek Biodiversity experiment is representative of all grasslands; rather it allows us to experimentally test hypotheses regarding controls on microbial diversity at local scales. Unimodal relationships between resource availability and diversity have been observed in many biotic communities at local scales (Groner \& Novoplansky 2003; Rajaniemi 2003; Chase \& Ryberg 2004), but at larger regional scales, positive linear relationships may occur (Chase \& Ryberg 2004) making relationships scale-dependent. The same patterns may occur with soil microbial communities, and scale-dependence or independence would affect global estimations of microbial species richness (Green et al. 2004). Generalities can only be made with more experimentation, but our observations provide a model with which to explore hypotheses concerning the controls on soil microbial diversity.

In conclusion, the relationship between resource availability and fungal diversity observed in this study parallels similar relationships reported for plant communities in many parts of the world, suggesting that the same underlying mechanisms determine the diversity of organisms ranging from fungi to trees (Tilman 1982). Taken together, these observations indicate that a fundamental underlying mechanism causes the diversity of presumably competing organisms to be a unimodal function of a limiting resource. Although our current results do not resolve the debate over the causative mechanisms, the demonstration that this unimodal pattern occurs in soil fungal communities may allow for its eventual resolution. We suggest that the time scale of competitive interactions in microbial communities may make the soil community an ideal system in which to test the various hypotheses that have been proposed to explain the relationship between diversity and resource availability (Zhou et al. 2002; Rajaniemi 2003). Furthermore, it suggests that the link between plant diversity and the diversity of microorganisms is at best indirect, thus potentially explaining the weak plant diversity-microbial diversity relationships observed in terrestrial ecosystems.

\section{ACKNOWLEDGEMENTS}

We would like to thank Troy Mielke and the CCNHA student interns for assistance with field sampling. We would also like to thank Rytas Vilgalys, Ron Ormeland, Larry Miller, George Kling, Kurt Pregitzer, and Deborah Goldberg for their reviews of the manuscript. This project was supported by National Research Initiative Competitive Grant no. 2003-35107-13743 from the USDA Cooperative State Research, Education, and Extension Service. 


\section{REFERENCES}

Acinas, S.G., Sarma-Rupavtarm, R., Klepac-Ceraj, V. \& Polz, M. (2005). PCR-Induced sequence artifacts and bias: insights from comparison of two $16 \mathrm{~S}$ rRNA clone libraries constructed from the same sample. Appl. Environ. Microbiol., 71, 8966-8969.

Alvarez, R. \& Alvarez, C.R. (2000). Soil organic matter pools and their associations with carbon mineralization kinetics. Soil Sci. Soc. Am. J., 64, 184-189.

Brodie, E., Edwards, S. \& Clipson, N. (2003). Soil fungal community structure in a temperate upland grassland soil. FEMS Microb. Ecol., 45, 105-114.

Broughton, L.C. \& Gross, K.L. (2000). Patterns of diversity in plant and soil microbial communities along a productivity gradient in a Michigan old-field. Oecologia, 125, 420-427.

Carney, K.M., Matson, P.A. \& Bohannan, B.J.M. (2004). Diversity and composition of tropical soil nitrifiers across a plant diversity gradient and among land-use types. Ecol. Lett., 7, 684-694.

Chase, J.M. \& Ryberg, W.A. (2004). Connectivity, scale-dependence, and the productivity-diversity relationship. Ecol. Lett., 7, 676-683.

Chazdon, R., Colwell, R., Denslow, J. \& Guaringuata, M. (1998). Statistical methods for estimating species richness of woody regeneration in primary and secondary rain forests of northeastern costa rica. In: Forest Biodiversity Research, Monitoring and Modeling (eds Dallmeier, F. \& Comiskey, J.). UNESCO, Parthenon Publishing, Paris, Pearl River, NY, pp. 285-309.

Colwell, R.K. (1994-2004). EstimateS: Statistical Estimation of Species Richness and Shared Species from Samples. Available at http://purl.oclc.org/estimates.

Conant, R.T., Paustian, K. \& Elliott, E.T. (2001). Grassland management and conversion into grassland: effects on soil carbon. Ecol. Appl., 11, 343-355.

Gans, J., Wolinsky, M. \& Dunbar, J.M. (2005). Computational improvements reveal great bacterial diversity and high metal toxicity in soil. Science, 309, 1387-1390.

Green, J.L., Holmes, A.J., Westoby, M., Oliver, I., Briscoe, D., Dangerfield, M. et al. (2004). Spatial scaling of microbial eukaryote diversity. Nature, 432, 747 (3 pages).

Groner, E. \& Novoplansky, A. (2003). Reconsidering diversityproductivity relationships: directness of productivity estimates matters. Ecol. Lett., 6, 695-699.

Hawksworth, D.L. (2004). Fungal diversity and its implications for genetic resource collections. Studies in Mycology, 50, 9-18.

Hooper, D.U., Bignell, D.E., Brown, V.K., Brussaard, L., Dangerfield, J.M., Wall, D.H. et al. (2000). Interactions between aboveground and belowground biodiversity in terrestrial ecosystems: patterns, mechanisms, and feedbacks. Bioscience, 50, 1049-1061.

Horner-Devine, M.C., Leibold, M.A., Smith, V. \& Bohannan, B.J.M. (2003). Bacterial diversity patterns along a gradient of primary productivity. Ecol. Lett., 6, 613-622.

Hughes, J.B. \& Bohannan, B.J.M. (2004). Application of ecological diversity statistics in microbial ecology. In: Molecular Microbial Ecology Manual (eds Kowalchuk, G.A., de Bruiijn, F.J., Head, I.M., Akkermans, A.D.L. \& Elsas, J.D.V.). Kluwer Academic Publishers, Dordrecht, pp. 1321-1344.

Kassen, R., Buckling, A., Bell, G. \& Rainey, P.B. (2000). Diversity peaks at intermediate productivity in a laboratory microcosm. Nature, 406, 508-512.
Kennedy, A.C. \& Smith, K.L. (1995). Soil microbial diversity and the sustainability of agricultural soils. Plant Soil, 170, 78-86.

Kowalchuk, G.A., Buma, D.S., de Boer, W., Klinkhamer, P.G.L. \& van Veen, J.A. (2002). Effects of above-ground plant species composition and diversity on the diversity of soil-borne microorganisms. Antonie Leeuwenhoek, 81, 509-520.

Legendre, P. \& Anderson, M.J. (1999). Distance-based redundancy analysis: testing multispecies responses in multifactorial ecological experiments. Ecol. Monogr., 69, 1-24.

Lodge, D.J. (1997). Factors related to diversity of decomposer fungi in tropical forests. Biodiver. Conserv., 6, 681-688.

Maclean, C.R., Dickson, A. \& Bell, G. (2005). Resource competition and adaptive radiation in a microbial microcosm. Ecol. Lett., 8, 38-46.

Mikola, J. \& Setala, H. (1998). No evidence of tropic cascades in an experimental microbial-based food web. Ecol. Lett., 79, 153-164.

Ovington, J., Heitkamp, D. \& Lawrence, D. (1963). Plant biomass and productivity of prarie, savanna, oakwood, and maize field ecosystems in central Minnesota. Ecology, 44, 52-63.

Ovreas, L. \& Torsvik, V. (1998). Microbial diversity and community structure in two different agricultural soil communities. Microb. Ecol., 36, 303-315.

Rajaniemi, T.K. (2003). Explaining productivity-diversity relationships in plants. Oikos, 101, 449-457.

Ter Braak, C.J.F. (1986). Canonical correspondence analysis: a new eigenvector technique for multivariate direct gradient analysis. Ecology, 67, 1167-1179.

Tiedje, J.M., Asuming-Brempong, S., Nusslein, K., Marsh, T.L. \& Flynn, S.J. (1999). Opening the black box of soil microbial diversity. Appl. Soil Ecol., 13, 109-122.

Tilman, D. (1982). Resource Competition and Community Structure. Princeton University Press, Princeton, NJ.

Tilman, D., Wedin, D. \& Knops, J. (1996). Productivity and sustainability influenced by biodiversity in grassland ecosystems. Nature (London), 379, 718-720.

Tilman, D., Raich, P.B., Knops, J., Wedin, D., Mielke, T. \& Lehman, C. (2001). Diversity and productivity in a long-term grassland experiment. Science, 294, 843-845.

Torsvik, V., Goksoyr, J. \& Daae, F. (1990). High diversity in DNA of soil bacteria. Appl. Environ. Microbiol., 56, 782-7.

Tunlid, A. (1999). Anniversary minireview - molecular biology: a linkage between microbial ecology, general ecology and organismal biology. Oikos, 85, 177.

Wardle, D.A. (1992). A comparative assessment of factors which influence microbial biomass carbon and nitrogen levels in soil. Biol. Rev., 67, 321-358.

White, T.J., Bruns, T., Lee, S. \& Taylor, J.W. (1990). Amplification and direct sequencing of fungal ribosomal RNA genes for phylogenetics. In: PCR Protocols: A Guide to Methods and Applications (eds Innis, M.A., Gelfand, D.H., Sninsky, J.J. \& White, T.J.). Academic Press, Inc., New York, pp. 315-322.

Worm, B., Lotze, H.K., Hillebrand, H. \& Sommer, U. (2002). Consumer versus resource control of species diversity and ecosystem functioning. Nature, 417, 848-851.

Zak, D.R., Grigal, D.F., Gleeson, S. \& Tilman, D. (1990). Carbon and nitrogen cycling during secondary succession: constraints on plant and microbial biomass. Biogeochem, 11, 111-129.

Zak, D.R., Tilman, D., Parmenter, R.R., Rice, C.W., Fisher, F.M., Vose, J. et al. (1994). Plant production and doil microorganisms 
in late-successional ecosystems - a continental-scale study. Ecology, 75, 2333-2347.

Zak, D.R., Holmes, W.E., White, D.C., Peacock, A.D. \& Tilman, D. (2003). Plant diversity, soil microbial communities and ecosystem function: are there any links? Ecology, 84, 2042-2050.

Zelles, L., Bai, Q.Y., Rackwitz, R., Chadwick, D. \& Beese, F. (1995). Determination of phospholipid- and lipopolysaccharidederived fatty acids as an estimate of microbial biomass and community structures in soils. Biol. Fertil. Soils, 19, 115-123.

Zhou, J., Xia, B., Treves, D.S., Wu, L.Y., Marsh, T.L., O’Neill, R.V. et al. (2002). Spatial and resource factors influencing high microbial diversity in soil. Appl. Environ. Microbiol., 68, 326-334.

\section{SUPPLEMENTARY MATERIAL}

The following supplementary material is available for this article:

Appendix S1 Description of OTUs in cedar creek clone library.

Table S1 Identification of basidiomycete operational taxonomic units in soils from the Cedar Creek Natural History Area.

Table S2 Identification of ascomycete operational taxonomic units in soils from the Cedar Creek Natural History Area.
Table S3 Identification of zygomycete, glomeromycetes, chytridiomcota, plasmodiophorida, and unknown operational taxonomic units in soils from the Cedar Creek Natural History Area.

This material is available as part of the online article from http://www.blackwell-synergy.com/doi/full/10.1111/ j.1461-0248.2006.00965.x.

Please note: Blackwell Publishing are not responsible for the content or functionality of any supplementary materials supplied by the authors. Any queries (other than missing material) should be directed to the corresponding author for the article.

Editor, Marcel Holyoak

Manuscript received 6 March 2006

First decision made 13 April 2006

Second decision made 17 June 2006

Third decision made 26 July 2006

Manuscript accepted 29 July 2006 